\title{
Randomized Clinical Trial of LigaSure Haemorrhoidectomy versus Open Diathermy Haemorrhoidectomy
}

\author{
Islam $\mathrm{MT}^{1}$, Rahman $\mathrm{MH}^{2}$, Rahman $\mathrm{MM}^{3}$, Ahmed $\mathrm{S}^{4}$, Begum $\mathrm{N}^{5}$
}

\begin{abstract}
Introduction: Haemorrhoidectomy is the most effective and definitive treatment for grade III or IV haemorrhoids. The traditional surgical approaches include the open (Milligan-Morgan) and the closed (Ferguson and Parks) haemorrhoidectomy. Both procedures entail similar complications, in particular protracted postoperative pain that causes longer hospital stays. Recently, a variety of instruments have been used in an attempt to reduce postoperative pain and a quicker return to normal activities. A new option in performing Milligan -Morgan haemorrhoidectomy involves the LigaSure system, a bipolar electrothermal vessel sealing device.
\end{abstract}

Objective: The randomized clinical trial was carried out to see the benefits of using LigaSure over monopolar diathermy in haemorrhoid surgery in terms of operating time, postoperative pain and complications.

Materials and Methods: This randomized clinical trial was carried out in the Department of Surgery at Combined Military Hospital, Dhaka. The study was conducted for a period about two years. The sample size was one hundred cases of haemorrhoidectomy divided into 50 cases of two groups, which is LigaSure haemorrhoidectomy and open diathermy haemorrhoidectomy. Patients were included in the trial if they had symptomatic prolapsing internal haemorrhoids. All patients were randomized using sealed envelopes. Patients were blinded to the type of surgery performed. Patients kept a record of postoperative pain by means of a visual analogue scale. Symptom control and patient's satisfaction were assessed at 12 weeks' follow-up. LigaSure haemorrhoidectomy was performed by the mediumsized LigaSure ${ }^{\mathrm{TM}}$ forceps.
Results: The operating time was less in LigaSure haemorrhoidectomy (mean 7.7 min with range of 4 to $16 \mathrm{~min}$ ) as compared with open diathermy haemorrhoidectomy (mean 18.2 with range 7-24 min) $(p<0.001)$. The median postoperative pain score was 4.3 (range 1-8.5) in the LigaSure group and 7.0 (range 3-9) in the open diathermy haemorrhoidectomy group. The difference was statistically significant $(p<0.001)$. The median number of administrations of analgesia in postoperative period was less in the LigaSure group (10 with range 4-20) as compared with the open diathermy group (19.5 with range 6-24) $(p<0.001)$. There were five cases of complications in LigaSure haemorrhoidectomy group, whereas eleven cases developed complications in open diathermy haemorrhoidectomy group. The complications were postoperative bleeding, urinary retention and anal fissure.

Conclusion: Evidence to date confirms that LigaSure haemorridectomy is an effective technique. LigaSure appeared to be an effective tool for the dissection and haemostasis required for an excisional haemorrhoidectomy procedure.

Key-words: LigaSure vessel system, LigaSure haemorrhoidectomy, Diathermy haemorrhoidectomy.

\section{Introduction}

Haemorrhoidectomy is the most effective and definitive treatment for grade III or IV haemorrhoids1. At present, the traditional surgical approaches include the open (Milligan-Morgan) and the closed (Ferguson and Parks) haemorrhoidectomy ${ }^{1-4}$. However, both procedures entail similar complications, in particular blood loss and protracted postoperative pain that cause longer hospital stays ${ }^{1,5}$.

1. Col Md Tanvirul Islam, MBBS, FCPS, Fellow Colon and Rectal Surgery (NUH,Singapore), Classified Specialist in Surgery, CMH, Dhaka; 2. Brig Gen Md Habibur Rahman (Retd), MBBS, FCPS, Professor \& Adviser Specialist (Surgery), CMH, Dhaka;

3. Brig Gen Md Mahbubur Rahman, MBBS, FCPS, Professor of Surgery, Classified Specialist in Surgery, AFMC, Dhaka;

4. Col Siddique Ahmed (Retd), MBBS, FCPS, Associate Professor \& Classified Specialist in Surgery, AFMC, Dhaka; 5. Lt Col Nasrin Begum, MBBS, MPhil, Graded Specialist in Anatomy, AFMC, Dhaka. 
The postoperative pain is linked to excessive tissue trauma involving sensitive perianal skin and anoderm $^{5}$. Much of this discomfort may arise from thermal injury because of electrocoagulation and from the presence of sutures. Use of preoperative lactulose and metronidazole to reduce perioperative pain ${ }^{6,7}$ has recently been included in evidence-based guidelines for the practice of haemorrhoidectomy ${ }^{8}$. Recently, a variety of instruments including circular stapler, ultrasonic scalpel, laser and a bipolar electro-thermal device are used with an attempt to reduce postoperative pain and blood loss, and to permit fast wound healing and a quicker return to normal acitivites ${ }^{9-14}$. A new option in performing Milligan-Morgan haemorrhoidectomy involves the LigaSure system, a bipolar electrothermal vessel sealing device ${ }^{15,16}$. LigaSureTM (Valleylab, Boulder, Colorado, USA) is a novel haemostatic device designed primarily for use in abdominal surgery. LigaSure vessel sealing system is a bipolar electrothermal device that seals blood vessels by an optimized combination of pressure and radiofrequency ablation that permanently changes collagen and elastin within the vessel wall ${ }^{2}$ to achieve complete and permanent fusion of the vessel lumen. The LigaSure system allows effective, bloodless haemorrhoid excision with minimal tissue injury, reducing postoperative pain, infection rate, time for wound healing and time to return to normal activities $^{13,15,17,18}$. Several randomized trials comparing LigaSure and conventional haemorrhoidectomy have shown that the LigaSure procedure is a safe and simple method of improving surgical outcome. However, these series have involved limited numbers of patients with only a short term follow-up ${ }^{13,15,17 ; 19-22}$. Some Western studies have shown benefits of using LigaSure over diathermy in terms of operative time, postoperative pain and wound healing ${ }^{13,15,17}$. This study will certainly provide some knowledge and information about the better option for haemorrhoidectomy. The LigaSure is available in Combined Military Hospital, Dhaka. The proper use of this device can provide a better outcome in haemorrhoid surgery in terms of operation time, postoperative pain, wound healing and complication.

\section{Materials and Methods}

The study was a randomized clinical trial, carried out to see the benefits of using LigaSure over monopolar diathermy in terms of operating time, postoperative pain and complications. The study was carried out in the Department of Surgery at Combined Military Hospital, Dhaka Cantonment. The study was conducted for a period about two years from September 2008 to July 2009 and again from August 2011 to October 2012 .The sample size was one hundred cases of haemorrhoidectomy divided into Group-I consisting of 50 cases of LigaSure haemorrhoidectomy and Group-II consisting of 50 cases of open diathermy haemorrhoidectomy. Patients were included in the trial if they had symptomatic prolapsing internal haemorrhoids and were medically fit for spinal or general anaesthesia. Exclusion criteria were haematological disorders, regular use of anticoagulants, immunosuppressants or analgesics; American Society of Anesthesiologists grade III or IV, pregnancy, obesity (body mass index greater than $35 \mathrm{~kg} / \mathrm{m} 2$ ), those undergoing simultaneous procedures for fissure or fistula, and those previously operated upon for haemorrhoids and these having insulin-dependent diabetes mellitus, epilepsy, known hypersensitivity to local anaesthetics; and drug or alcohol abuse. All patients were randomized to receive either LigaSure haemorrhoidectomy or open haemorrhoi- dectomy using sealed envelopes. The randomization was nonconsecutive in nature. Randomization was performed in the operating theatre just prior to surgery. Patients were blinded to the type of surgery performed. Written informed consent was obtained from all patients who were admitted for haemorrhoidectomy with symptomatic prolapsing haemorrhoid. In both groups a standard preoperative protocol was followed, which included 20 $\mathrm{ml}$ lactulose twice daily from the day before operation to aid in defecation after the operation and $500 \mathrm{mg}$ metronidazole given intravenously at the start of the operation. After surgery all patients received lactulose $20 \mathrm{ml}$ per day for two weeks, and metronidazole $400 \mathrm{mg}$ three times daily for one week. On the day of operation diclofenac sodium injection was used to control postoperative pain. Oral diclofenac sodium $50 \mathrm{mg}$ two times daily, on demand, never more than three times per day, were prescribed to all patients for postoperative analgesia from the first postoperative day. All patients were asked to clean the wound by sitz bath twice daily. Patients kept a record of postoperative pain by means of a visual analogue scale. Patients were familiarized with an 11-point visual analogue pain score from 0 to 10 , before operation. 
The patients were asked to record before bed-time their maximum pain score for the day. Pain scores were recorded for seven days from the first postoperative day; from this a weekly mean score was calculated. The patients were also asked to record the total number of analgesic tablet taken for that day. Subjective postoperative assessment of pain was evaluated by considering the dose of analgesics used by each patient daily. All data concerning duration of surgery, postoperative pain, analgesic requirement, and complications were recorded. Patients were assessed at the first follow-up visit at the end of second week when wound was examined. Subsequent follow-up was at third, fourth and sixth weeks. Complete wound healing was defined as absence of swelling of the wound. Symptom control and overall patient's satisfaction were assessed at 12 weeks' follow-up. All patients were encouraged to contact the authors if necessary. In both groups haemorrhoidectomy was undertaken using a Sim's or Pratts rectal speculum with the patient in the lithotomy position. All procedures were performed under general or spinal anaesthesia. Milligan-Morgan techniques for open diathermy haemorrhoidectomy were performed by either a consultant or a higher surgical trainee. All LigaSure procedures were performed by same surgeon. No anal canal pack dressing was employed in either group. After the haemorrhoids had been prolapsed out from the anal canal with an artery forceps, LigaSure haemorrhoidectomy was performed by applying the medium-sized LigaSure ${ }^{\mathrm{TM}}$ forceps close to the edge of each haemorrhoid together with any associated skin tag. Completion of coagulation was signalled by the feedback sensors and the tissue was excised along the line of coagulum. Repeated applications of the device were performed and excision was continued into the anal canal, lifting the haemorrhoidal tissue from the internal anal sphincter, to the level of the vascular pedicle, which was finally divided. The area was then inspected with rectal speculum to ensure haemostasis. Surgical suture was used either to ligate pedicle or for haemostasis when required. In the diathermy group, haemorrhoidectomy was performed by submucosal dissection of the haemorrhoidal tissue from the internal sphincter using standard monopolar diathermy. Pedicles were transfixed, taking care to avoid incorporation of the underlying sphincter; haemorrhoids were excised and the wounds left open.
At the end of the study, individual interview schedule and checklist were checked to see completeness and consistency of data. Data analysis was performed using the Statistical Package for the Social Sciences for Windows version 12.0 (SPSS, Chicago, Illinois, USA). After controlling for the homogeneity of the groups, to test for statistical significance, the t-test was used for continuous variables. The Mann-Whitney $U$ test was used to establish the difference between LigaSure and open haemorrhoidectomy with respect to the duration of operation, postoperative pain and analgesic requirement. A value of $p<0.05$ was considered statistically significant.

\section{Results}

Hundred patients were included in this study. There were $32(64 \%)$ men and $18(36 \%)$ women in the LigaSure haemorrhoidectomy group, and $34(68 \%)$ men and $16(32 \%)$ women in open diathermy haemorrhoidectomy group. The mean age was 36.9 (range 20-65) years in LigaSure haemorrhoidectomy group and 40.3 (range 21-65) year in open haemorrhoidectomy group with no statistical difference $(p=0.283)$ in patients characteristics (Table-I).

Table-I: Patient characteristics.

\begin{tabular}{|l|c|c|c|}
\hline & $\begin{array}{c}\text { LigaSure } \\
(\mathrm{n}=50)\end{array}$ & $\begin{array}{c}\text { Diathermy } \\
(\mathrm{n}=50)\end{array}$ & $\mathrm{P}$ \\
\hline Sex & & & \\
Male & $32(64 \%)$ & $34(68 \%)$ & \\
Female & $18(36 \%)$ & $16(32 \%)$ & \\
\hline Mean (range) age (years) & $36.9(20-65)$ & $40.3(21-65)$ & $\mathrm{p}=0.283$ \\
\hline
\end{tabular}

*Student's t- test (Independent Sample T test)

The operating time was less in LigaSure haemorrhoidectomy group (mean 7.7 min with range 4-16 $\mathrm{min}$ ) as compared with open diathermy haemorrhoidectomy group (mean 18.2 with range 7-25 min) $(p<0.001)($ Fig-1).

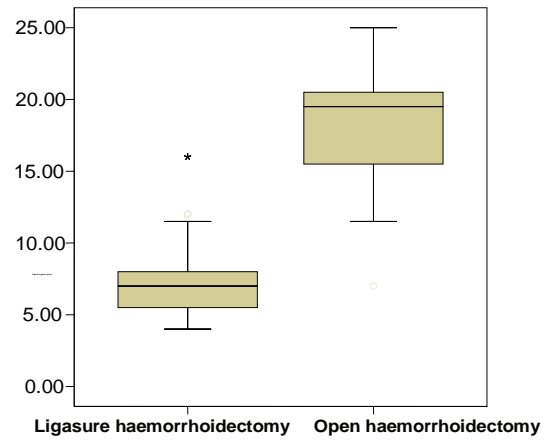

Fig-1: Mean operating time for LigaSure and open diathermy haemorrhoidectomy. Boxes denote the range $\mathrm{P}<0.001$ (Mann-Whitney U test) 
The median postoperative pain score was 4.3 (range 1- 8.5) in the LigaSure group and 7.0 (range $3-9)$ in the open diathermy haemorrhoidectomy group. The difference was statistically significant $(p<$ 0.001) (Fig-2).

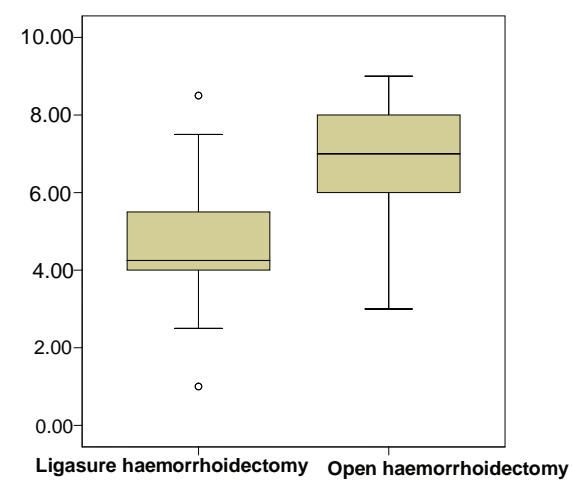

Fig-2: Comparison of median daily pain score following LigaSure and open diathermy haemorrhoidectomy. Boxes denote the range $p<0.001$ (Mann-Whitney $U$ test).

The median number of analgesia administered in postoperative period was less in the LigaSure group10 with range 4-20) as compared with the open group (19.5 with range 6-24) $(p<0.001)$. The clinical outcomes of two studies are shown in Table-II.

Table-II: The clinical outcomes of two study groups.

\begin{tabular}{|l|c|c|c|}
\hline Variables & $\begin{array}{c}\text { LigaSure } \\
(\mathbf{n}=50)\end{array}$ & $\begin{array}{c}\text { Diathermy } \\
(\mathbf{n}=50)\end{array}$ & $\mathbf{P}$ \\
\hline $\begin{array}{l}\text { Operating } \\
\text { time }\end{array}$ & $\begin{array}{c}\text { Mean 7.7 } \\
(\text { range 4-16) min }\end{array}$ & $\begin{array}{c}\text { Mean 18.2 } \\
\text { (range 7-24) min }\end{array}$ & $<0.001$ \\
\hline $\begin{array}{l}\text { Postoperative } \\
\text { pain score }\end{array}$ & $\begin{array}{c}\text { Median 4.3 } \\
\text { (range 1-8.5) }\end{array}$ & $\begin{array}{c}\text { Median 7.0 } \\
\text { (range 3-9) }\end{array}$ & $<0.001$ \\
\hline $\begin{array}{l}\text { Number of } \\
\text { analgesia }\end{array}$ & $\begin{array}{c}\text { Median 10 } \\
\text { (range 4-20) }\end{array}$ & $\begin{array}{c}\text { Median 19.5 } \\
\text { (range 6-24) }\end{array}$ & $<0.001$ \\
\hline
\end{tabular}

*Mann-Whitney $U$ test

Only two cases of LigaSure group required haemostatic sutures. There were five complications in the LigaSure haemorrhoidectomy group and eleven complications in open diathermy haemorrhoidectomy group (Table-III).

Table-III: Complications in two patients.

\begin{tabular}{|l|c|c|}
\hline Complications & $\begin{array}{c}\text { LigaSure } \\
(\mathbf{n = 5 0})\end{array}$ & $\begin{array}{c}\text { Diathermy } \\
(\mathbf{n}=\mathbf{5 0})\end{array}$ \\
\hline Bleeding & 2 & 4 \\
\hline Urinary retention & 1 & 5 \\
\hline Anal fissure & 2 & 4 \\
\hline
\end{tabular}

The complications were postoperative bleeding, urinary retention and anal fissure. All urinary retentions developed in the evening of the day of operation and responded to temporary bladder catheterization. Patients of both groups complained of protracted pain after defecation resulting from the development of anal fissure. All of them responded to treatment with stool softeners, sitz bath and topical glyceryl trinitrate paste. All patients with secondary bleeding had single episode of haemorrhage in both groups but did not require any blood transfusion or operative maneuvour. At 12th week follow up, there was no difference in over all outcomes between the two groups of patients.

\section{Discussion}

Haemorrhoidectomy is the procedure that cures prolapsing haemorrhoids most effectively ${ }^{1}$. The widely performed excision-ligation procedure first described by Milligan and Morgan ${ }^{3}$ can be bloody and is associated with troublesome postoperative pain. Haemorrhoidectomy using diathermy excision has been shown to be associated with less bleeding, a shorter operating time and a lower postoperative analgesic requirement, but the technique is not intrinsically less painful than conventional haemorrhoidectomy ${ }^{23}$.

Different techniques and devices have been developed to overcome postoperative pain, including modifications of the techniques, introduction of new surgical instruments, perioperative use of lactulose, metronidazole, and the addition of lateral internal sphincterotomy or the intraoperative injection of botulinum neurotoxin $^{6,7,9-14,23-26}$. The LigaSure vessel-sealing system allows complete coagulation of blood vessels along with confinement of the thermal spread to within 2 $\mathrm{mm}$ of adjacent tissue and also limited tissue charring. Its application results in a discrete line of coagulation that allows bloodless haemorrhoid excision, making it an ideal instrument for haemorrhoidectomy. This study shows that the new technique offers advantages over conventional open diathermy haemorrhoidectomy as confirmed by other studies ${ }^{2,17}$. A significant decrease in operative time when compared to open diathermy haemorrhoidectomy was also observed. In this study, mean operating time ( $\mathrm{min}$ ) was 7.7 (range 4-16) in LigaSure group and 18.2(range 7-25) in 
open diathermy group. Tan $\mathrm{KY}$ et $\mathrm{al}^{27}$ reported mean operative time $(\mathrm{min})$ as 9.4 and 18.2 in LigaSure group and open diathermy group respectively whereas Palazzo FF et $\mathrm{al}^{17}$ reported 5.1 (range 2-9) and 9.2 (range 7.6-14.1) min of median duration of operation in LigaSure group and open diathermy group respectively. The absolute bloodlessness is the characteristic of the LigaSure haemorrhoidectomy; it offers better visibility and therefore more accurate dissection. The absence of blood in the operative field is such that no time is required to secure haemostasis ${ }^{17}$ and as a consequence the mean operating time in this study was less than half in LigaSure group than open diathermy group.

This study demonstrates that the LigaSure group experienced less postoperative pain than the open diathermy group $(P<0.001)$. In this series median postoperative pain score was 4.3 (range 1-8.5) in LigaSure group and 7(range 3-9) in open diathermy group. Muzi $M G$ et $a^{2}$ reported pain score as 1.5(range 0-3) and 3.3 (range 2-6) in LigaSure group and open diathermy group respectively whereas Milito $G$ et $\mathrm{al}^{15}$ reported median postoperative pain score 4.7 (range 2-8) in LigaSure group and 5.2 (range 2-8) in diathermy group. Anal spasm after haemorrhoidectomy has been implicated in postoperative pain and poor wound healing ${ }^{8,28}$. It has been postulated that LigaSure haemorrhoidectomy is associated with reduced anal spasm $^{29}$. This is because the collateral damage with LigaSure is less than that with diathermy. The median postoperative analgesic requirement following the LigaSure haemorrhoidectomy was lower than that of open diathermy haemorrhoidectomy. However, in this study the pain on the day of operation was not measured. The incidence of different complication of this study and comparison with other series are shown in Table-IV.

Table-IV: Comparison of postoperative complications reported by other randomized controlled trials comparing LigaSure (LS) with open diathermy (OD) haemorrhoidectomy.

\begin{tabular}{|l|c|c|c|c|}
\hline Reference & $\begin{array}{c}\text { Number of } \\
\text { patient }\end{array}$ & Bleeding & $\begin{array}{c}\text { Urinary } \\
\text { retention }\end{array}$ & $\begin{array}{c}\text { Anal } \\
\text { fissure }\end{array}$ \\
\hline Present series & LS 50 & LS 2 & LS 1 & LS 2 \\
& OD 50 & OD 4 & OD 5 & OD 4 \\
\hline Chang YC et al ${ }^{33}$ & LS 30 & LS 3 & LS 1 & LS 0 \\
& OD 31 & OD 3 & OD 2 & OD 0 \\
\hline \multirow{2}{*}{ Milito G et al ${ }^{24}$} & LS 29 & LS 1 & LS 1 & LS 0 \\
& OD 27 & OD 2 & OD 1 & OD 0 \\
\hline Jayne DG et al ${ }^{19}$ & LS 20 & LS 1 & LS 1 & LS 1 \\
& OD 20 & OD 1 & OD 0 & OD 1 \\
\hline
\end{tabular}

In this study there have been no unexpected complications. In contrast, circular stapling haemorrhoidectomy has been followed by reports of serious complications including pelvic sepsis ${ }^{30}$ and anastomotic stenosis ${ }^{31}$. Furthermore, failure to deal with external haemorrhoidal components and skin tags can lead to an unsatisfactory cosmetic result in some 20-40 per cent of patients treated with circular stapling $^{32}$. Although residual skin tags are believed to shrivel over time, this will be verified only with further long- term follow-up. This problem is avoided with the use of LigaSure diathermy, which can deal effectively with both internal and external haemorrhoidal components, giving excellent cosmesis.

\section{Conclusion}

Evidence to date confirms that LigaSure haemorridectomy is an effective technique. The new technique is safe, comparatively simple and easy to learn; it is bloodless and rapid to perform. LigaSure haemorrhoidectomy takes significantly less time to complete and is associated with significantly less postoperative pain and reduction in the amount of postoperative analgesia than open diathermy haemorrhoidectomy. LigaSure appears to be an effective tool for the dissection and haemostasis required for an excisional haemorrhoidectomy procedure.

\section{References}

1. MacRae HM, McLeod RS. Comparison of haemorrhoidal treatment modalities.A meta-analysis. Dis Colon Rectum 1995; 38: 687-94.

2. Muzi MG, Milito G, Nigro C, Cadeddu F, Andreoli F, Amabile D, Farinon AM. Randomized clinical trial of LigaSure and conventional diathermy haemorrhoidectomy. Br J Surg 2007; 94: 937-42.

3. Milligan ET, Morgan CN, Jones LE, et al. Surgical anatomy of the anal canal, and the operative treatment of haemorrhoids. Lancet 1937; 2: 119-24.

4. Ferguson JA, Heaton JR. Closed haemorr- hoidectomy. Dis Colon Rectum 1959; 2: 176-9.

5. Golighten J, Graham NG, Cleark CG, De Dohmal IT, Giles $G$. The value of stretching the anal sphincter in the relief of post-haemorrhoidectomy pain. Br J Surg 1969; 56: 859-61. 
6. London NJ, Bramley PD, Windle R. Effect of four days of preoperative lactulose on post haemorrhoidectomy pain:results of placebo controlled trial. $\mathrm{Br}$ Med $\mathrm{J}$ 1987; 295: 363-4.

7. Carapeti EA, Kamm MA, McDonald PJ, Phillips RKS.Double-blind randomised controlled trial of effect of metronidazole on pain after day-case haemorrhoidectomy. Lancet 1998; 351: 169-72.

8. Cheetham MJ, Phillips RKS. Evidence-based practice in haemorrhoidectomy. Colorectal Dis 2001; 3: 126-34.

9. Mehigan BJ, Monson JR, Hartley JE. Stapling procedure for haemorrhoids versus Milligan Morgan haemorrhoidectomy: randomised controlled trial. Lancet 2000; 355: 782-5.

10. Senagore A, Mazier WP, Luchtefeld MA, MacKeigan JM, Wengert T. Treatment of advanced haemorrhoidal disease:a prospective, randomized comparison of cold scalpel vs. contact Nd:YAG laser. Dis Colon Rectum 1993; 36: 1042-9.

11. Tan JJ, Seow-Choen F. Prospective, randomized trial comparing diathermy and Harmonic Scalpel haemorrhoidectomy. Dis Colon Rectum 2001; 44: 677-9.

12. Armstrong DN, Ambroze WL, Schertzer ME, Orangio GR. Harmonic Scalpel_vs. electrocautery haemorrhoidectomy: a prospective evaluation. Dis Colon Rectum 2001; 44: 558-64.

13. Jayne DG, Botterill I, Ambrose NS, Brennan TG, Guillou PJ, O'Riordain DS. Randomized clinical trial of Ligasure versus conventional diathermy for day-case haemorrhoidectomy. Br J Surg 2002; 89: 428-32.

14. Ganio E, Altomare DF, Gabrielli F, Milito G, Canuti S. Prospective randomized multicentre trial comparing stapled with open haemorrhoidectomy. Br J Surg 2001; 88: 669-74.

15. Milito G, Gargiani M, Cortese F (2002) Randomised trial comparing LigaSure hemorrhoidectomy with the diathermy dissection operation. Tech Coloproctol 6:171-5.

16. Diamantis T, Kontos M, Arvelakis A, Syroukis S, Koronarchis D, Papalois A, Agapitos E, Bastounis E, Lazaris AC. Comparison of monopolar electrocoagulation, bipolar electrocoagulation, Ultracision, and Ligasure. Surg Today 2006; 36: 908-13.

17. Palazzo FF, Francis DL, Clifton MA. Randomized clinical trial of LigaSureTM versus open haemorrhoidectomy. Br J Surg 2002; 89: 154-7.

18. Thorbeck CV, Montes MF. Haemorrhoidectomy: randomised controlled clinical trial of LigaSureTM compared with Milligan-Morgan operation. Eur J Surg 2002; 168:482-4.

19. Sayfan J, Becker A, Koltun L. Sutureless closed hemorrhoidectomy: a new technique. Ann Surg 2001; 234:21-4.
20. Franklin EJ, Seetharam S, Lowney J, Horgan PG.Randomized, clinical trial of LigasureTM versus conventional diathermy in hemorrhoidectomy. Dis Colon Rectum 2003; 46:1380-3.

21. Chung YC, Wu HJ. Clinical experience of sutureless closed hemorrhoidectomy with LigaSureTM. Dis Colon Rectum 2003; 46: 87-92.

22. Wang JY, Lu CY, Tsai HL, Chen FM, Huang CJ, Huang YS et al. Randomized controlled trial of LigaSureTM with submucosal dissection versus Ferguson hemorrhoidectomy for prolapsed hemorrhoids. World J Surg 2006; 30: 462-6.

23. Seow-Choen F, Ho YH, Ang HG, Goh HS. Prospective randomized trial comparing pain and clinical function after conventional scissors excision / ligation vs. diathermy excision without ligation for symptomatic prolapsed haemorrhoids. Dis Colon Rectum 1992; 35: 1165-9.

24. Roswell M, Bello M, Hemingway DM. Circumferential mucosectomy (stapled haemorrhoidectomy) versus conventional haemorrhoidectomy: randomized controlled trial. Lancet 2000; 355: 779-81.

25. Galizia G, Lieto E, Castellano P, Pelosio L, Imperatore V, Pigantelli C. Lateral internal sphincterotomy together with haemorrhoidectomy for treatment of haemorrhoids: a randomized prospective study. Eur J Surg 2000; 166: 223-8.

26. Patti R, Almasio PL, Muggeo VMR, Buscemi S, Arcara M, Matranga S, Di Vita G. Improvement in wound healing after haemorrhoidectomy: a double-blind, randomized study of botulinum toxin injections. Dis Colon Rectum 2005; 48: 2173-9.

27. Kwok SY, Chung CC, Tsui KK, Li MKW. A double blind, randomized trial comparing Ligasure and Harmonic Scalpel haemorrhoidectomy. Dis Colon Rectum 2005; 48: 344-8.

28. Tan KY, Sng KK, Eu KW et al. Randomized clinical trial of 0.2 per cent glyceryl trinitrate ointment for wound healing and pain reduction after open diathermy haemo -rrhoidectomy. Br J Surg 2006; 93:1464-8.

29. Ramcharan KS, Hunt TM. Anal stenosis after LigaSure hemorrhoidectomy. Dis Colon Rectum 2005; 48:1670-1.

30. Cheetham MJ, Mortensen NJ, Nystrom PO, Kamm MA, Phillips RK. Persistent pain and faecal urgency after stapled haemorrhoidectomy. Lancet 2000; 356: 730-3.

31. Ho YH, Cheong K, Tsang C, Ho J, Eu K, Tang CL et al. Stapled hemorrhoidectomy -cost and effectiveness. Randomized, controlled trial including incontinence scoring, anorectal manometry, and endoanal ultrasound assessments at up to three months. Dis Colon Rectum 2000;43: 1666-75.

32. Engel AF, Eijsbouts QA. Haemorrhoidectomy: painful choice. Lancet 2000; 355: 2253-4. 